\title{
On orbit MTF measurement of remote sensing camera based on wavelet transform (Notice of Removal)
}

Guangze Li, Xiaodong Wang, Huaide Zhou, Zhihang Hao

Guangze Li, Xiaodong Wang, Huaide Zhou, Zhihang Hao, "On orbit MTF measurement of remote sensing camera based on wavelet transform (Notice of Removal)," Proc. SPIE 6031, ICO20: Remote Sensing and Infrared Devices and Systems, 60310G (2 February 2006); doi: 10.1117/12.667929 


\title{
On orbit MTF measurement of remote sensing camera based on wavelet transform (Notice of Removal)
}

\author{
Proc. SPIE 6031, 60310G (2006); http://dx.doi.org/10.1117/12.667929
}

Online Publication Date: 2 February 2006

Retracted from Publication: 8 August 2008

Conference Date: 26 August 2005

Conference Location: Changchun, China

Conference Title: ICO20: Remote Sensing and Infrared Devices and Systems

Conference Chairs: J ingshan Jiang, O. Y. Nosach, Jiaqi Wang

\section{Guangze Li and Huaide Zhou}

Changchun Institute of Optics, Fine Mechanics and Physics (China) and Graduate School of Chinese Academy of Sciences (China)

Xiaodong Wang and Zhihang Hao

Changchun Institute of Optics, Fine Mechanics and Physics (China)

This paper (SPIE Paper 60310G) was removed from the SPIE Digital Library on 8 August 2008 upon learning that portions of the paper are identical or similar to material contained in a Master's Thesis by Taeyoung Choi at South Dakota State University in 2002 titled "IKONOS Satellite on Orbit Modulation Transfer Function (MTF) Measurement using Edge and Pulse Method, " without attribution or credit to the source.

As stated in the SPIE Publication Ethics Guidelines, "SPIE defines plagiarism as the reuse of someone else's prior ideas, processes, results, or words without explicit attribution of the original author and source, or falsely representing someone else's work as one's own. Unauthorized use of another researcher's unpublished data or findings without permission is considered to be a form of plagiarism even if the source is attributed. SPIE considers plagiarism in any form, at any level, to be unacceptable and a serious breach of professional conduct."

It is SPIE policy to remove such papers and to provide citations to original sources so that interested readers can obtain the information directly from these sources. 